\title{
Online Teaching and Learning Challenges in a Mountainous and Remote Area of Vietnam
}

\begin{abstract}
Van Pang Lo
Dien Bien Teacher Training College

Corresponding author. Email: lovanpang@gmail.com

ABSTRACT

This qualitative study explored the key challenges of teachers and students living in remote rural mountainous regions of northern Vietnam. This study was carried out in Dien Bien Province, one of Vietnam's most disadvantaged areas. Even though this issue has been studied by many researchers and educators around the world and Vietnam, it is not paid enough attention to remote and mountainous areas like Dien Bien. Information was gathered using multiple interviews with 04 teachers and 04 students at 02 High Schools in Dien Bien Province. An analysis of the results of this study resulted in the identification of key challenges shaping the teaching and learning outcomes of studied participants. Key influences identified were: technological challenges, pedagogical challenges, learning and teaching environment challenges, and social challenges. This study suggests some solutions for both government and individuals so as to have better educational outcomes.
\end{abstract}

Keywords: Remote, rural, Dien Bien, mountainous, online teaching, online learning, challenges.

\section{INTRODUCTION}

Dien Bien Province is located in the North-West of Vietnam. It covers $95413300 \mathrm{~km}^{2}$ with a population of 601700 people [1]. It is far from Hanoi, the capital city, about $500 \mathrm{~km}$. Moreover, it is a mountainous and remote area with 21 different ethnic groups such as Kinh, Thai, Mong, Dao, Kho Mu, Tay, Muong living together. About $90 \%$ of these people are farmdependent and earn a very modest income with only 515000VND per month. 39.9\% of Dien Bien Province's population belongs to the poor, the highest rate in Vietnam [1]. Up to now, Dien Bien Province is still at the top of the list of the most disadvantaged area of Vietnam.

In 2020, due to the outbreak of Covid-19, all schools in Vietnam were closed for a few months so as to cope with the pandemic. So as to catch up with the school year curriculum, the Ministry of Education and Training had to ask schools and teachers to be swift to online lessons; this way of teaching caused both teachers and students many difficulties in their work [2]. The situation is much worse in Dien Bien as students do not have electronic gadgets and stable internet to follow the lessons while teachers lack online teaching skills computer literacy. This study tries to find out the barriers encountered by teachers and students at Dien Bien High Schools in their online work during the period of Covid-19.

\section{LITERATURE REVIEW}

The covid-19 pandemic has changed the ways of life of many people around the world. Governments had to take many measures so as to ease the spread of this pandemic. Education is one of the most sectors which seriously affected. The classical lessons were completely stopped throughout Vietnam from February to July 2020. Moving from conventional ways of teaching and learning to virtual and online ones causes many difficulties for both teachers and students. This also widened the gap between the urban students and rural students in their learning. Students in rural and remote areas feel excluded as they cannot access authentic and reliable online learning resources and did not have electric devices, and teachers were not welltrained for this teaching approach [3].

Mohmmed et al. (2020) argued that global education had been heavily affected by Covid-19. Many schools 
and students in middle-east experienced lockdown, curfew, and self-isolation [4]. The most affected groups are the students and teachers working and living in mountainous and remote areas. They are struggling with the sudden changes of teaching and learning methods they have not prepared beforehand. In addition, the schools in these places are lack of essential, necessary conditions for virtual teaching and learning [5]. Online instruction needs a rapid digitalization of curriculum [7] while teachers and students in these places are not well prepared for the digital time [8]. Avila et al. claimed that people in rural and remote areas in South Africa live in poor social-economic infrastructure, poor education, and healthcare. They also do not have enough transportation, market, electricity, and internet to support their lives [9]. In addition, people in rural Africa cannot afford the modern technology which is needed for online teaching and learning [10].

Ferri et al. studied teaching and learning online in Italy, and they found that the schools in rural areas met many challenges brought by technology, such as unreliable internet connection, students' lack of electronic gadgets. Moreover, teachers were also lack of computer skills and online teaching approaches as well as online resources. Students felt isolated because they did not have face to face interaction with their teachers and peers. Many students also said that they did not receive enough support from their parents as their father or mother was often busy with their job [11].

In the Netherlands, the above problems happened to students and teachers who worked at schools from the lower ones to the higher ones during the Covide-19 period [12]. In Ghana and Malaysia, the same matters are experienced by both teachers and students; in many places, The Internet is not available or not reliable for students to learn $[13,14]$.

The Covid-19 puts teachers and students in a new teaching and learning age. Both schools and society have to adapt to new teaching and learning approaches. Throughout Vietnam, the schools were passive in coping with the teaching and learning at the Covid-19 time. Schools and communities in rural and remote areas are the ones who need much support from wider communities. Students in mountainous and remote areas are the most affected because they do not have facilities for teaching and learning online [15]. This issue has been studied by many international and domestic scholars, but only in other countries or large cities, but not in Dien Bien Province. This paper will explore the challenges and difficulties in Dien Bien, a rural, mountainous, and remote area of Vietnam.

\section{METHODOLOGY}

\subsection{Research question}

The research questions underpinning this study are:

1. What challenges are teachers in Dien Bien facing in their online teaching during the Covid-19 period?

2. What challenges are students in Dien Bien facing in their online learning during the Covid-19 period?

\subsection{Theoretical Framework}

This study is formed and shaped by the Community of Inquiry approach. This concept was first used by early pragmatists Peirce, C. S., Addams, J., and Dewey, J. [16]. Because a community is defined as a group of individuals sharing the same issue, problem, or interest, and community is the one that produces knowledge [17]. In addition, the community can optimize the online learning environment, and the interaction between teacher and students as well as critical thinking is supported [18].

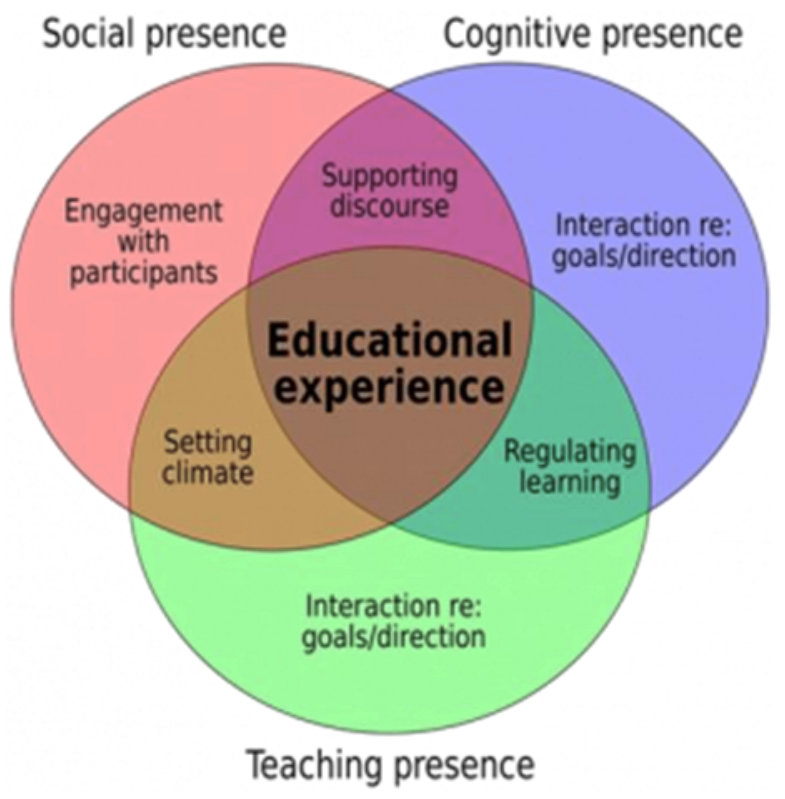

Figure 1 Elements of an educational experience [19]

Students in rural Dien Bien tend to live in small communities. They share the same language and culture as well as issues when they are learning online with their teachers. Each school is isolated from the other as the geographical barrier, so teachers can only see the ones who work at the same school. As a consequence, teachers also encountered the same problems when they offered lessons during the Covid-19 time. Through those problems, both teachers and students gained more knowledge of online learning and teaching. Moreover, they could equip some online skills for themselves to be more effective teachers and learners in the future. 


\subsection{Recruitment of participants}

The researcher decided to recruit only 04 senior secondary school students and 04 of their teachers for this study because students at this level would be able to talk about their online learning experiences during the Covid-19 time. As older students, they are also more likely to express and reflect on their schooling experiences than younger students and better understand what research is and concepts of confidentiality and informed consent.

\subsubsection{Recruitment of teacher participants}

The researcher had met with the year 11 and 12 teachers and informed them of his study and their participation; recruitment was by informed consent and self-selection. Interested teachers were invited to talk further with the researcher to clarify information or ask further questions before giving their informed consent. All teachers were required to sign a consent form before participating in the study.

\subsubsection{Recruitment of Student Participants}

The researcher privately met with the student to ensure they were fully informed about the study and what would be expected of them. If the student wanted to be involved after this, the researcher would arrange a meeting with the parents to seek their informed consent.

\subsection{Data collection}

Data were collected through multiple semistructured interviews with students and teachers. The interviews were conducted face-to-face in a private room at school. The interviews were audio-recorded. Before conducting the interviews, many informal conversations had been carried out with the teacher and student participants so as to gain the trust from them.

\subsection{Data analysis}

Interview records were transcribed and typed into Microsoft Word files. Separate case studies were developed by triangulating interview data from the students and teachers [20]. After that, the researcher tried to find out and analyze the commonalities and differences between the case studies.

\section{RESULTS AND DISCUSSION}

After analyzing the collected data, the problems encountered by teachers and students were grouped into technological challenges, pedagogical challenges, learning and teaching environment challenges, and social challenges.

\subsection{Technological challenges:}

Both teachers and students often experienced technical difficulties in their work. Teaching and learning online is suddenly applied to all schools throughout the country from February to July 2020, so teachers and students were passive in their work. A teacher shared her feelings and experience:

We haven't got enough time to prepare computer skills for ourselves. The schools and education systems are passive too. They do not know how to do with an urgent situation like this. We were told to teach online for students, but we do not know how to do it.

Another issue is that teachers did not have time to learn how to use the online applications for their teaching as they had never thought that the online ones would completely replace the conventional lessons. People who cannot use technology effectively in their work tend to lack technical skills or other skills such as sustaining concentration or problem-solving. They often lose their confidence, self-direction, or motivation [21]. In addition, they also have limited necessary skills to find and choose appropriate web sources for their work [22]. Another teacher said:

Normally, I just use Microsoft office for making lesson plans and present my work to students. When moving to teach online, things are completely different. Teaching online is not as simple as we thought. We need to know how to use an online platform such as Zoom, Google Meet, or Microsoft Meetings. They are too big to get the hang of it within a short time.

Poor internet connection impedes online classrooms and prevents learners from having good learning outcomes [23]. Both teachers and students were not happy with their internet connection and the quality of internet service. She said that it was time-consuming so as to set up an online lesson.

Internet is a nightmare for me. When I set up my class and ready for teaching, then it went off. I had to start everything from scratch.

A student shared his story that the internet is a nuance for his learning:

I wish I could have a better internet provider. I was often interrupted by the internet. It is very unpleasant. When I was following lessons, it went out, so I lost many parts of the lesson. I do not know who to ask or seek for help.

Hundreds of poor income family's children seem to be left behind in online learning as only a small number 
of rural students can access to internet and possess a device, and the gap is widening day by day [24]. Many studied students do not have enough electronic devices to join an online lesson because their families cannot afford one. Many students were excluded from school because of their economic problems.

I was very miserable when my teachers told us to have lessons via laptops or iPad. How can I participate in lessons while there is nothing in my family? I ask my parents to buy me a laptop, but the cheapest one is almost 10 million VND, so it is out of the question.

\subsection{Pedagogical challenges:}

Besides technological challenges, teachers also met many difficulties in the ways of teaching. Teaching online is completely different from traditional teaching, and new teaching methods are needed [25]. An effective teacher at face-to-face teaching cannot guarantee success in the online class [26]. Teaching online is completely new to teachers in remote areas like Dien Bien as they got familiar with the face-to-face classes. Many teachers complained that they could not manage their online class and did not know if their students followed their lessons.

When I gave online lessons, I did not know if my students understood what I said or not. I cannot see their face and behaviors. When I taught them in class, I could say what my students thought as I could see it through their faces and interactions.

Teacher participants claimed that it took them much time to prepare an online lesson as they had to transfer the conventional lesson plans to the electronic ones. Many teachers complained that they lacked computer skills, so the electronic lesson plan is a barrier.

I have to admit that I am bad at the computer. I feel uncomfortable and embarrassed when using the computer to offer an online lesson. In addition, I have to transfer the paper lesson plans to an electronic one, and it is really a hard thing for me.

Technology distraction is another problem with teachers and students. Some teachers argued that their students liked playing video games more than learning. In addition, telephone and messaging are problems for both teachers and students.

I figured out that many of my students, especially, boy students used learning time to play games. It is hard to tell them to stop doing that as I could not see what they were doing then. I just told them to stop playing, but I do not think it is effective at all.
I feel uncomfortable with the phone and message. My students' phones kept ringing while I was giving lessons to the class. It distracted other students from learning.

Giving and checking homework is a big issue to teachers as many of their students do not have an email account. In addition, a large number of students do not have an electronic device. It is really a tough problem because almost family are farm dependent, and they have a very poor income to equip their child with a laptop or computer.

Homework is a big problem for me because most of my students belong to low-income families, so they do not have enough money to buy a laptop for their children. The email account is another problem. Many of my students said that they do not have one as they are too young to have an email. It is very hard for me to give them homework and check their work.

\subsection{Learning and teaching environment challenges}

The teaching and learning environment is really a challenge to both teachers and students. Distraction is a challenging issue affecting students' attention, learning, motivation, and persistence in their learning [27]. Due to their typical characteristics and culture, many of them claimed that they did not have a private space to learn at home. In addition, they were often distracted by the member of the family and their guests, so they could not concentrate on their learning.

It is really problematic when I am in the middle of teaching, and someone comes to see me. They know I am at home, so I cannot ignore it. I have to see them for a while when they come to my house.

The home environment is simple and not as structured as a classroom at school. A little change in the household arrangement can foster online learning productivity [28]. In contrast, the students in Dien Bien's remote places did not have a proper place for their learning and were struggling with completing their schoolwork online.

When I had a lesson, my parents and relatives kept moving around, and they talked very loud. I tried to tell them to be quiet, but they did not listen to me as they had an axe to grind. I wish I could have a private room at home so I could concentrate on my learning.

McKie said that students' learning outcomes were heavily affected by study space; learners could learn better if they could have a quiet and appropriate learning 
space and vice versa [29]. Many students do not have a desk to learn because their house is very simple. They just have some essential things such as stools, dining tables or coffee tables. It affects them much the outcome of their learning.

My family is too poor to have a desk for me to learn like the others. I have to write on my laps, and it is very hard for me to keep up the lesson. I did not tell my teachers as I am too shy to tell them about my situation. Anyway, they couldn't offer me any help even I told them.

\subsection{Social challenges}

The lack of social interaction is one of the most severe matters for teaching and learning online [30]. Even if a person has regular online communications with others, they still feel isolated [31]. Many teachers and students confirmed that they were deserted from the other and wanted to have physical interaction with the others as the normal day.

It's very boring to study online at home. I miss my friends and teachers. It is very hard to do things on your own. It is very easy to feel sleepy when I have online lessons, and even I try to stay awake and follow the lessons.

Traditional classes foster a sense of community and connectedness, while the online learning and teaching environment cannot do this [32]. Many teachers said that they lacked support from their colleagues and management board in their teaching.

I feel very lonely at my work. Whenever I meet any difficulties in my teaching, such as technical issues, I do not have anyone to seek help. When I was at school, I could immediately get help from my colleagues as each of them is specialized in one field.

Whenever I have any difficulties with my homework, I do not know to whom to talk. Normally, I could ask my friends or teachers. But at this time of Covid-19, I am not allowed to approach them.

\section{SUGGESTED SOLUTIONS FOR BETTER ONLINE EDUCATION IN RURAL AND REMOTE AREAS}

- Teachers and students should be equipped with a certain level of digital literacy via technology forums, online conferences, or social networking sites.
- Technical support should be available for both teachers and students when the class is on.

- Government and schools should find some financial support for extremely low-income families with purchasing electronic devices for their children in remote areas.

- Different learning contexts, environments, and cultural settings should be addressed in online learning and teaching to create a sense of belonging among the students.

- The emotional connection should be facilitated through casual and learner-centred conversations between teachers and students.

- The flexible learning environment should be set up for learners to organize their own learning and educational pathways.

- Learning communities among students should be created for students who share learning goals, ideas, and problems.

- A friendly atmosphere should be encouraged so as to minimize isolation among teachers and students by using social networks, blogs, or online social hubs.

- Live meetings, phone calls, discussions, and chats should be used regularly by teachers to help their students in their learning.

\section{LIMITATION OF THE STUDY}

This study has many limitations that need taking into account when considering the findings. It took only a small sample size, and it is unknown how well some of the challenges identified in this study apply to other rural and remote students in Vietnam. In order to have a better understanding of the situation, a bigger size of a sample is needed, and the scope of the study needed to be widened.

This study excluded children who had never gone to school or who had stopped going to school in Dien Bien Province. So as to identify the challenges that other students face, a deeper study is needed to carry out.

Information for this study was gathered by means of semi-structured interviews. Additional sources of data such as classroom observation, group interviews, or information from students' parents could enhance the study's credibility and validity.

One-on-one conversations with an adult such as a researcher are very uncommon in the rural and remote schools in Dien Bien. Interviews with a peer may have 
resulted in greater comfort and greater disclosures of schooling experiences.

\section{CONCLUSION}

Online teaching and learning in rural and remote areas like Dien Bien Province are problematic to both teachers and students. They met many difficulties in their work, such as technological literacy, teaching methodology, teaching and learning environment, and social isolation. In order to mitigate the negative effect and optimize the advantages of online education, both teachers and students need much support from the government and the education system. In addition, the students from extremely low-income families should be given much more support and attention from both teachers and society; thus, they are not left behind in online learning.

\section{REFERENCES}

[1] GSO, Statistical Yearbook of Vietnam, Statistical Publishing House, Hanoi, 2019

[2] M. Linh, T. Chau, Khó khăn trong dạy và học trực tuyến, $\quad 2020 . \quad$ http://quangtritv.vn/tin-tucn8863/kho-khan-trong-day-va-hoc-truc-tuyen.html

[3] B. Dube, Rural Online Learning in the Context of COVID-19 in South Africa: Evoking an inclusive Education Approach, Multidisciplinary Journal of Educational Research, 2020, pp. 135-157. http://dx.doi.org/10.447/remie.2020.5607

[4] A. O. Mohmmed, B. A. Khidhir, A. Nazeer, V. J. Vijayan, Emergency remote teaching during Coronavirus pandemic: Innovative Infrastructure Solutions, 2020.

[5] Eder R (2020) The remoteness of remote learning. J Interdisc Stud Educ 9(1):168-17

Stud Educ 9(1):168-171Proceedings of the Formal Methods for Eternal Networked Software Systems (SFM), Springer, Berlin, Heidelberg, 2011, pp. 53-

[6] G.D. Penna, B. Intrigila, I. Melatti, E. Tronci, M.V. Zilli, Bounded probabilistic model checking with the muralpha verifier, in: A.J. Hu, A.K. Martin (Eds.), Proceedings of the Formal Methods in Computer-Aided Design, Springer, Berlin, Heidelberg, 2004, pp. 214-229. DOI: https://doi.org/10.1007/978-3-540-30494-4_16

[7] E. Clarke, O. Grumberg, S. Jha, et al., Counterexample-guided abstraction refinement, in: E.A. Emerson, A.P. Sistla (Eds.), Computer Aided Verification, Springer, Berlin, Heidelberg, 2000, pp. 154-169. DOI: https://doi.org/10.1007/10722167_15
[8] H. Barringer, R. Kuiper, A. Pnueli, Now you may compose temporal logic specifications, in: Proceedings of the Sixteenth Annual ACM Symposium on the Theory of Computing (STOC), ACM, 1984, pp. 51-63. DOI: https://doi.org/10.1145/800057.808665

[9] A. Pnueli, In transition from global to modular temporal reasoning about programs, in: K.R. Apt (Ed.), Logics and Models of Concurrent Systems, Springer, Berlin, Heidelberg, 1984, pp. 123-144. DOI: https://doi.org/10.1007/978-3-642-82453-1_5

[10] B. Meyer, Applying "Design by Contract", Computer 25(10) (1992) 40-51. DOI: https://doi.org/10.1109/2.161279

[11] S. Bensalem, M. Bogza, A. Legay, T.H. Nguyen, J. Sifakis, R. Yan, Incremental component-based construction and verification using invariants, in: Proceedings of the Conference on Formal Methods in Computer Aided Design (FMCAD), IEEE Press, Piscataway, NJ, 2010, pp. 257-256.

[12] H. Barringer, C.S. Pasareanu, D. Giannakopolou, Proof rules for automated compositional verification through learning, in Proc. of the 2nd International Workshop on Specification and Verification of Component Based Systems, 2003.

[13] M.G. Bobaru, C.S. Pasareanu, D. Giannakopoulou, Automated assume-guarantee reasoning by abstraction refinement, in: A. Gupta, S. Malik (Eds.), Proceedings of the Computer Aided Verification, Springer, Berlin, Heidelberg, 2008, pp. 135-148. DOI: https://doi.org/10.1007/978-3540-70545-1_14

[14] B. N. Yusuf, Are we prepared enough? A case study of challenges in online learning in a private higher learning institution during the Covid-19 outbreaks. Adv. Soc. Sci. Res. J. 2020, 7, pp. 205-212. https://journals.scholarpublishing.org/index.php/ASSRJ/ article/view/8211

[15] Dương Kim Anh, Việt Nam: Covid-19 và thách thức đối với ngành giáo dục, Friedrich Ebert Stiftung, accessed December $24^{\text {th }} 2020$, https://www.fes-vietnam.org/vi/vnnews-events-publications-detail/viet-nam-covid-19-vathach-thuc-doi-voi-nganh-giao-duc/

[16] P. M. Shields, The Community of Inquiry: Insights for Public Administration from Jane Addams, John Dewey and Charles S. Peirce. Presented at the Public Administration Theory Network, Portland Oregon, 1999.

[17] D. Dumitru, Communities of inquiry. A method to teach. Procedia - Social and Behavioral Sciences 33, 2012, pp. $238-242$.

[18] D. R. Garrison, T. Anderson, \& W. Archer, Critical inquiry in a text-based environment: Computer conferencing in higher education. The Internet and Higher Education, 2(2), 1999, pp. 87-105. 
[19] D. R. Garrison, T. Anderson, W. Archer, The first decade of the community of inquiry framework: A retrospective. The Internet and Higher Education. 13(1), 2010, pp. 5-9.

[20] R. K. Yin, Case study research: design and methods. Thousand Oaks: Sage Publications, 2003.

[21] B. Lockitt, Adult, community and work based learning: elearning 3T productions, Cheadle, UK, 2004.

[22] J. Dron, Control and constraint in e-learning: Choosing when to choose Idea Group Publishing, London, 2007.

[23] E. A. Eisya, Poor internet connection, lack of devices hinder online learning: Ministry, The Jakarta Post, accessed December $24^{\text {th }} \quad 2020$, https://www.thejakartapost.com/news/2020/12/01/poorinternet-connection-lack-of-devices-hinder-onlinelearning-ministry.html.

[24] J. Salman, Hundreds of thousands of students still can't access online learning, Hechingerreport, accessed December $24^{\text {th }}$, 2020. https://hechingerreport.org/hundreds-of-thousands-ofstudents-still-cant-access-online-learning/

[25] L. Compton, Preparing language teachers to teach language online: a look at skills, roles, and responsibilities. Computer Assisted Language Learning, 22(1), 2009, pp. 73-99.

[26] N. Davis \& R. Rose, Professional developments for virtual schooling and online learning, 2007, http://www.inacol.org/research/docs/NACOL_PDforVSa ndOlnLrng.pdf

[27] J. A. Beyea, E. Wong, M. Bromwich, W. W. Weston, \& K. Fung, Evaluation of a particle repositioning maneuver web-based teaching module. Laryngoscope, 118(1), 2008, pp. 175-180.

[28] Misha Ketchell, 5 ways to support online homeschooling through the coronavirus pandemic, the conservation, accessed December $24^{\text {th }} \quad 2020$, https://theconversation.com/5-ways-to-support-onlinehomeschooling-through-the-coronavirus-pandemic$\underline{144147}$

[29] Anna McKie, Lack of study space and poor connections hinder online learning, the world university rankings, accessed December 24 $4^{\text {th }} \quad 2020$, https://www.timeshighereducation.com/news/lack-studyspace-and-poor-connections-hinder-online-learning

[30] L. Olesova, D. Yang, and J. C. Richardson, "CrossCultural Differences in Undergraduate Students' Perceptions of Online Barriers." Journal of Asynchronous Learning Networks 15(3), 2011, pp. 6880 .

[31] J. Delahunty, I. Verenikina, and P. Jones, "SocioEmotional Connections: Identity, Belonging and Learning in Online Interactions - A Literature Review." Technology, Pedagogy and Education, 23(2), 2014, pp. 243-265.

[32] K. Phirangee, A. Malec, "Othering in Online Learning: An Examination of Social Presence, Identity, and Sense of Community." Distance Education: Special Issue: Social Presence and Identity in Online Learning, 38(2), 2017, pp. 160-172. 